\title{
Aprendizagem do diálogo nas tecituras entre vida, formação e trabalho
} docente

\author{
Dialogue learning in the tissues between life, training and teacher work \\ Aprendizaje del diálogo en los tejidos entre la vida, la formación y el trabajo \\ docente
}

\author{
Elisangela André da Silva Costa ${ }^{2}$ \\ Maria Socorro Lucena Lima ${ }^{3}$
}

\begin{abstract}
Resumo: No contexto da sociedade contemporânea, de onde emergem políticas educacionais pautadas no neoliberalismo, tornam-se comuns práticas educativas assentadas numa racionalidade técnica que reduz os horizontes formativos à perspectiva bancária, visando resultados quantitativos. Neste cenário, surgem desafios políticos, epistemológicos e pedagógicos que afetam diretamente a formação, a vida e o trabalho dos professores, sobretudo no que se refere ao diálogo que tem se tornado, cada vez mais difícil e necessário. Este estudo objetiva discutir fundamentos, temas e desafios da dialogicidade na formação docente. Metodologicamente utiliza a abordagem qualitativa, analisando relatos autobiográficos produzidos por professores de uma escola pública cearense. Foram identificados desafios de aprendizagem do diálogo e o reconhecimento deste como possibilidade de construção de uma educação crítica e emancipatória que oportunize ao docente reconhecer-se como autor de sua história e de sua profissão.
\end{abstract}

Palavras-chave: Políticas educacionais brasileiras. Dialogicidade. Formação de professores. Trabalho docente.

\begin{abstract}
In the context of contemporary society, from which educational policies based on neoliberalism emerge, educational practices based on a technical rationality that reduces the training horizons to the banking perspective, aiming at quantitative results, become commonplace. In this scenario, political, epistemological and pedagogical challenges arise that directly affect the education, life and work of teachers, especially as regards the dialogue that has become increasingly difficult and necessary. This study aims to discuss fundamentals, themes and challenges of dialogicity in teacher education. Methodologically uses the qualitative approach, analyzing autobiographical reports produced by teachers of a public school in Ceará. Challenges of learning about dialogue were identified and its recognition as a possibility of building a critical and emancipatory education that enables teachers to recognize themselves as the author of their history and profession.
\end{abstract}

Keywords: Brazilian educational policies. Dialogicity. Teacher training. Teaching work.

Resumen: En el contexto de la sociedad contemporánea, de donde surgen políticas educativas basadas en el neoliberalismo, las prácticas educativas basadas en una racionalidad técnica que reduce los horizontes de capacitación a la perspectiva bancaria, con el objetivo de obtener resultados cuantitativos, se vuelven comunes. En este escenario, surgen desafíos políticos, epistemológicos y pedagógicos que afectan directamente la educación, la vida y el trabajo de los docentes, especialmente en lo que respecta al diálogo que se ha vuelto cada vez más difícil y necesario. Este estudio tiene como objetivo discutir los fundamentos, temas y desafíos de la dialogicidad en la formación docente. Utiliza metodológicamente el enfoque cualitativo, analizando informes autobiográficos producidos por docentes de una escuela pública en Ceará. Se identificaron los desafíos de aprender sobre el diálogo y su reconocimiento como una posibilidad de construir una educación crítica y emancipadora que permita a los maestros reconocerse a sí mismos como los autores de su historia y profesión.

Palabras clave: Políticas educativas brasileñas. Dialogicidad. Formación de profesores. Trabajo docente.

\footnotetext{
${ }^{1}$ Submetido em: 02 out. 2019 - Aceito em: 04 jan. 2020 - Publicado em: 19 jul. 2020

2 Universidade da Integração Internacional da Lusofonia Afro-Brasileira (UNILAB) - E-mail: elisangelaandre@unilab.edu.br

${ }^{3}$ Universidade Estadual do Ceará (UECE) - E-mail: socorro_lucena@uol.com.br
} 


\section{Introdução}

As políticas educacionais vigentes no Brasil, carregam marcas da sociedade contemporânea, que se expressam de diferentes formas, relacionando-se, sobretudo, à perspectiva neoliberal. A partir desta, evidenciam-se os princípios da produtividade e da performatividade que direcionam a ação das escolas e dos educadores à busca por resultados quantitativos. Como reflexo desta orientação, as práticas educativas acabam sendo influenciadas por uma racionalidade técnica que reduz os horizontes formativos à perspectiva bancária.

Neste cenário, de ameaça e perda da autonomia docente e da formação voltada à emancipação humana, surgem desafios políticos, epistemológicos e pedagógicos que afetam diretamente a formação, a vida e o trabalho dos professores. As referências relacionadas à vida, à cultura e às expectativas da escola, da comunidade e de seus sujeitos acabam sendo sufocadas diante da busca por resultados que são aferidos pelos sistemas de educação a partir de indicadores estabelecidos pelas avaliações de larga escala. Assim, na busca de figurarem entre os rankings das instituições de ensino de "excelência", os coletivos de trabalho têm suas estratégias de organização afetadas de forma negativa, sobretudo aquelas que se referem ao que não pode ser quantificado. Assim, o diálogo, enquanto referência formativa tem se tornado, cada vez mais difícil e necessário.

Diante do exposto, o presente estudo objetiva discutir fundamentos, temas e desafios da dialogicidade na formação docente, situados no contexto atual, marcado por profundas tensões e contradições. Metodologicamente foi utilizada a abordagem qualitativa, tendo como estratégias de aproximação com a realidade a revisão de literatura acerca das categorias dialogicidade, políticas educacionais e formação de professores, articulada à produção de relatos autobiográficos por professores que atuam em uma escola pública cearense, localizada no município de Acarape.

A partir da análise dos dados produzidos no campo de investigação, em uma perspectiva dialética de leitura da realidade, identificamos os desafios de aprendizagem do diálogo e o reconhecimento deste como possibilidade de construção de uma educação crítica e emancipatória que oportunize ao docente reconhecer-se como autor de sua história e de sua profissão.

\section{Políticas educacionais brasileiras e seus reflexos na formação e no trabalho docente}

O período que compreende as décadas finais do Século XX e as décadas iniciais do Século XXI traz para o contexto brasileiro importantes transformações que implicam de maneira direta no modo como a educação passou a se organizar.

O processo de reabertura democrática do Brasil, na década de 1980, foi marcado pela efervescência dos movimentos da sociedade civil organizada na luta pela garantia de direitos sociais. No que diz respeito à democratização do acesso da população brasileira aos processos 
educativos formais, constituíram-se como importantes marcos históricos a Constituição Federal Brasileira de 1988 (BRASIL, 1988) e a Lei de Diretrizes e Bases da Educação Nacional (LDB) no 9394/96 (BRASIL, 1996a) que expressam conquistas importantes para a coletividade, como o reconhecimento da educação enquanto "[...] dever da família e do Estado, inspirada nos princípios de liberdade e nos ideais de solidariedade humana [...]" que "[...] tem por finalidade o pleno desenvolvimento do educando, seu preparo para o exercício da cidadania e sua qualificação para o trabalho" (BRASIL, 1996a, Art. $2^{\circ}$ ).

A partir dessa referência, a citada lei, expressa de forma objetiva, os princípios que devem ser tomados como base para a organização do ensino, dentre os quais destacamos aqueles que dizem respeito à liberdade, presente nos processos de aprendizagem, ensino, pesquisa, pensamento, arte e saber; pluralismo das ideias e das concepções pedagógicas; respeito e apreço à liberdade e à tolerância; valorização da experiência oriunda de vivências extraescolares; estabelecimento de vínculos entre a educação escolar, o mundo do trabalho e as práticas sociais; apreço com a diversidade étnico-racial (BRASIL, 1996a, Art. $3^{\circ}$ ).

A partir do avanço no processo de democratização e da LDB n ${ }^{\circ}$ 9394/96 (BRASIL, 1996a), tivemos o desenvolvimento de políticas voltadas ao acesso, à permanência e ao sucesso dos educandos no contexto das instituições de ensino, sobretudo na Educação Básica. Dentre essas políticas, podemos mencionar algumas, como as que se relacionam: ao financiamento, como a criação na década de 1990 do Fundo de Manutenção e Desenvolvimento do Ensino Fundamental e de Valorização do Magistério (FUNDEF) (BRASIL, 1996b), posteriormente substituído pelo Fundo de Manutenção e Desenvolvimento da Educação Básica e de Valorização dos Profissionais da Educação (FUNDEB) (BRASIL, 2007); à organização curricular, que transitou pelos Parâmetros e Referenciais Curriculares lançados na década de 1990, pelas Diretrizes Curriculares Nacionais no início do presente Século e, atualmente, pela Base Nacional Comum Curricular (BNCC) que se encontra em processo de implantação, fornecendo referências para a estruturação dos projetos políticopedagógicos da educação básica; à implantação/aperfeiçoamento de estratégias de monitoramento e registro de dados que, articulados, traduzem elementos relativos à qualidade, como o censo escolar e o sistema de avaliação em larga escala; às estratégias de formação de professores, a exemplo de programas diversos como a Universidade Aberta do Brasil e o Programa Nacional de Formação de Professores da Educação Básica, entre tantos outros que permitiram aos docentes a obtenção das exigências formativas postas pela legislação educacional.

As ações e programas mencionados são apenas alguns, dentre as inúmeras propostas desenvolvidas ao longo das últimas décadas e traduziram, de modo significativo, a necessidade de preparação - que envolve planejamento e avaliação contínua - dos sistemas de ensino para lidar, de forma cada vez mais situada, com a realidade educacional do contexto brasileiro, desenhada a partir dos diferentes sujeitos que passaram a constituir e a reconfigurar a identidade das instituições de ensino, na perspectiva de uma cultura avaliativa (KÖNIG, 2007). Assim, para entender os novos desafios que se anunciam à educação, é importante estarmos atentos ao contexto, lançando olhares para o que ocorre dentro e fora da escola. 
Lendo criticamente o cotidiano da formação e do trabalho docente na atualidade, percebemos que na medida em que o Século XXI avança, a sociedade vem vivendo de forma cada vez mais intensa transformações em diferentes esferas, afetando de maneira direta a construção da subjetividade dos sujeitos e, como consequência, o papel e as formas de organização das instituições responsáveis pela sociabilidade e formação dos mesmos, como a escola.

Sintetizamos, no quadro 1, os contributos que Libâneo (2011) aponta, na obra "Adeus professor, adeus professora: novas exigências educacionais e profissão docente" e que nos auxiliam na identificação de tais transformações.

Quadro 1. Transformações vividas na sociedade contemporânea

\begin{tabular}{|c|c|}
\hline Esferas & Transformações \\
\hline Econômica & Globalização \\
& $\begin{array}{r}\text { Competitividade e mudança nos padrões de produção e consumo } \\
\text { Novas tecnologias afetando a organização do trabalho e o perfil do trabalhador } \\
\text { Novos padrões de qualificação profissional }\end{array}$ \\
\hline Política & Submissão das políticas sociais à perspectiva da economia mundial \\
& Redução do papel do Estado \\
\hline Ética & Padronização de hábitos de consumo \\
& Individualismo e egoísmo - naturalização da exclusão \\
\hline Vida cotidiana & Indução de novas necessidades \\
& Crescimento do poder dos meios de comunicação \\
\hline
\end{tabular}

Fonte: Adaptado de Libâneo (2011).

Ao tomar como referência a sociedade contemporânea e seus diferentes aspectos, o autor contextualiza a importância de repensar continuamente a formação e o trabalho docente, de forma historicamente situada, percebendo como as transformações vividas pela humanidade modificam as formas como lidamos com o conhecimento e com os processos de mediação que promovem sua construção. Assim, as formas de organização dos processos de ensinar e aprender têm sempre como referência o tipo de ser humano que queremos ajudar a formar e o tipo de sociedade que queremos ajudar a construir / manter / transformar. A partir desses pontos de partida são estabelecidos compromissos, através de políticas educacionais, que dizem respeito tanto aos conhecimentos considerados válidos, quanto aos princípios que devem nortear a abordagem metodológica e avaliativa presentes nos projetos políticopedagógicos das instituições de ensino.

Aqueles que lidam cotidianamente com o trabalho docente e com a formação desses profissionais vivenciam, hoje, uma alteração de eixo nos elementos considerados como referência para traduzir a qualidade dos processos formativos desenvolvidos pelas instituições de ensino. Estamos diante de dilemas não só pedagógicos, mas, sobretudo, políticos e éticos, que confrontam elementos como: inclusão x mérito; tradição x novidade; transformação x manutenção; emancipação x alienação; entre outros. Tais tensões expressam uma mudança paradigmática de valores, em que a perspectiva coletiva, democrática e solidária perde gradativamente espaço para valores próprios do neoliberalismo, como o individualismo, a competitividade e a exclusão.

Quase sempre as tensões supramencionadas decorrem das demandas que chegam aos 
gestores escolares e aos educadores através das políticas de resultado, de cunho neoliberal, que vêm ganhando força e tirando do processo pedagógico a sua essência enquanto elemento de formação humana numa perspectiva integral e emancipatória. Os professores desenvolvem suas práticas cercados por tensões que se originam, segundo Charlot (2016), das contradições presentes nas esferas econômica, social e cultural da sociedade contemporânea, tendo o seu trabalho desestabilizado pelas mesmas e sendo convidado, de forma permanente, a tomar posicionamentos que colocam em jogo o seu compromisso ético com a profissão.

Diante deste cenário, é necessário problematizar a formação inicial e continuada de professores, questionando o modo como lidam com essa realidade, tendo em vista que o neoliberalismo avança nas políticas educacionais e nas formas de organização pedagógica da escola, mas também, em outros aspectos. Dentre eles, destacamos as condições de vida e trabalho dos professores, que têm sua profissão cada vez mais marcada pela precarização, pela instabilidade e incerteza; os desafios relativos às condições materiais de existência da população em suas mais cruéis expressões, como o desemprego e a violência urbana, entre outras tantas questões que colocam em xeque as dimensões técnica, política, estética e ética da profissão (RIOS, 2010); os princípios da gestão empresarial que chegam às instituições de ensino demandando os melhores resultados com cada vez menos recursos, como reflexo da concepção reducionista de qualidade defendida pela perspectiva neoliberal.

De acordo com Silva (2001, p. 22-23) o discurso da Qualidade Total:

[...] reprime e desloca o discurso da igualdade/desigualdade, da justiça/injustiça, da participação política numa esfera pública de discussão e decisão, tornando quase impossível pensar numa sociedade e numa comunidade que transcendam os imperativos do mercado e do capital.

A ênfase na busca por resultados que possam traduzir-se em indicadores utilizados pelos sistemas de educação para aferir esta "qualidade" e conceder às escolas o status de instituições educacionais de "excelência" tem promovido a negação da dimensão política do papel da escola relacionada aos compromissos democráticos de superação das condições de desigualdade a partir dos processos formativos e a supervalorização da dimensão técnica, que desconsidera a realidade em que vivem os estudantes e as próprias escolas, interessando-se quase que exclusivamente pelas referências externas e pelos métodos que permitam chegar mais rápido aos resultados desejados nos processos avaliativos em larga escala. Tal movimento nos permite visualizar o retorno, potente, da racionalidade técnica que marcou significativamente o Brasil durante a década de 1970 e que reduzia a identidade do professor ao de um consumidor acrítico de conhecimentos produzidos por especialistas (COSTA, 2018).

Zeichner (2013), discutindo a formação de professores no contexto dos Estados Unidos, considerando que o país vem se constituindo de forma recorrente como referência para as reformas curriculares, ocorridas nas últimas décadas, em diferentes países, como o Brasil, aponta a existência de duas perspectivas que se contrapõem nos processos de formação inicial de professores: de um lado uma que simboliza a defesa dos processos amplos de profissionalização, com abrangente preparo profissional e desenvolvimento da carreira do magistério; e do outro a que se volta a uma formação de natureza estritamente 
técnica, ancorada no desenvolvimento de scripts de instrução que têm como referência a melhoria da pontuação dos estudantes em testes padronizados.

É necessário compreendermos a articulação deste fenômeno específico, com o fenômeno mais amplo de avanço do neoliberalismo nos diferentes campos, inclusive dos direitos sociais, compreendendo que o mesmo não é neutro. Pimenta e Lima (2019, p. 4) nos ajudam a compreender melhor tal questão quando afirmam:

\begin{abstract}
As prioridades das políticas neoliberais incidem negativamente sobre a formação de professores ao acentuar práticas de ensinar em detrimento de teorias e implementar sistemas de avaliação e premiação que precarizam o trabalho docente, instituindo bônus no lugar de aumento salarial. Essas e outras medidas somadas a tantas mais passam pela vida profissional dos professores sem que eles compreendam com clareza os determinantes e a intencionalidade de tais ações.
\end{abstract}

Ao enfatizarem o "como fazer" em detrimento do "todo fazer", os processos formativos, quer em nível inicial ou continuado, tiram do professor o direito de compreender de forma ampla e crítica as articulações que se tecem entre sua vida, sua formação e seu trabalho, mecanizando o processo de construção da identidade profissional, que se constitui como uma prática antidialógica que busca colonizar o pensamento dos professores (COSTA, 2018).

Compreendemos que para lidar de forma crítica e socialmente responsável com o exercício da profissão professor, no atual contexto, se faz imprescindível o reconhecimento do professor como sujeito, como intelectual capaz de ser autor de suas próprias práticas. Isto requer uma formação que coloque em discussão o contexto e seus desafios políticos, pedagógicos e epistemológicos, buscando na Pedagogia, enquanto ciência da educação, os conhecimentos teóricos necessários para compreendermos a realidade, tensa e contraditória, em que se insere a docência.

A dialogicidade proposta por Paulo Freire (1987) na obra "Pedagogia do Oprimido", perspectiva formativa tão atacada nos últimos tempos, configura-se como uma referência importante que simboliza a possibilidade de superação do autoritarismo presente na onda de racionalidade técnica, que avança nos campos de formação e trabalho docente e que desumaniza, cada vez mais, tanto educadores, quanto educandos.

\title{
Dialogicidade como fundamento necessário à formação de professores na atualidade
}

A partir das reflexões tecidas na seção anterior, acerca dos compromissos presentes nas políticas educacionais contemporâneas e seus reflexos na formação e no trabalho docente, chamamos atenção para a constante ameaça à autonomia desses profissionais em relação ao seu trabalho. Cada vez mais, as instituições de ensino são atravessadas pela perspectiva tecnicista e mecânica que emerge das estratégias de controle do trabalho docente, sendo exercidas por agentes externos às escolas e universidades (ZEICHNER, 2013). Para fazer frente a este desafio é necessária a defesa de uma formação ampla, rica em fundamentos teóricos e metodológicos que permitam a leitura crítica e a problematização da realidade, 
como condições necessárias à composição de perspectivas formativas que ao mesmo tempo que oportunizem a apropriação dos conhecimentos construídos historicamente pela humanidade, permitam, também, a construção de novos conhecimentos sobre os desafios presentes nos processos de ensinar e aprender.

Nesse sentido, a dialogicidade pode ser compreendida como uma postura política, pedagógica e epistemológica fundamental aos educadores e instituições de ensino para posicionar-se diante do autoritarismo que atualmente se manifesta de forma velada ou claramente exposta pelos governos e pelas políticas que implantam e implementam, nos convidando a pensar, na condição de educadores, sobre o lugar que ocupamos no desenvolvimento de nossa profissão.

As tentativas de desautorizar a expressão das falas de educandos e educadores, em nome da expressão de grupos privilegiados social, política e economicamente, é um fenômeno historicamente presente no contexto brasileiro (RIBEIRO, 2017) e, por mais denunciado e combatido que seja, mantém-se presente nos espaços sociais diversos, devendo ser, portanto, objeto de nossas permanentes reflexões e ações de resistência (FREIRE, 1967).

A imposição das formas de compreensão do mundo a partir de culturas que hegemonicamente se colocam como as mais válidas e importantes no contexto da sociedade se constitui como forma de opressão e de dominação que precisa ser criticamente entendida pelos sujeitos para que tenham condições de superá-las (FREIRE, 1987), fato que demanda o direito de cada um de nós a processos formativos pautados em uma perspectiva emancipadora.

Diante da necessidade de busca de referenciais que possam, através de uma sólida formação, fortalecer nossa ação no mundo, como sujeitos, faz-se necessário ressaltar que tal empreendimento não é tarefa fácil, tendo em vista que a Educação guarda em si um caráter contraditório revelado de maneira permanente nos movimentos de preservação e de transformação das culturas e das relações sociais estabelecidas entre os sujeitos. Tal movimento implica na necessária revisão das formas que nós, como educadores, fomos preparados para lidar com o exercício de ler criticamente nossa profissão e nos relacionarmos de forma dialógica com o conhecimento, com os indivíduos que os constroem e com os espaços onde se processa essa construção.

A obra "Pedagogia do Oprimido", escrita por Paulo Freire (1987), há 50 anos recémcomemorados, vem iluminando e fundamentando as discussões acerca da importância, da necessidade e da complexidade do diálogo. Escrita em um contexto de profundo avanço de forças conservadoras no Brasil, sob a presença de um governo militar instituído através de um golpe contra a democracia, o autor, transformando sua indignação e sofrimento diante dos retrocessos, violência e injustiças em um profundo ato de esperança, dedicou-se à sistematização, uma elaboração teórica historicamente situada e rica em reflexões que se mantém, mais do que nunca, atuais.

No cenário brasileiro do qual emergiu a inspiração para a escrita de "Pedagogia do Oprimido", direitos foram suprimidos, vozes foram silenciadas, o pensamento crítico foi combatido, a mobilização social duramente reprimida e o autoritarismo se impôs como 
principal característica do governo, materializada através do controle, repressão, da violência e perseguição política. Atualmente, com a reedição da perspectiva antidialógica e antidemocrática do contexto político brasileiro, a obra reafirma sua importância.

Este período histórico, extremamente difícil, da década de 1960, foi também um momento fértil e rico em reflexões e produções artísticas, culturais e acadêmicas que permitiram a reconfiguração das formas como os diferentes tipos de saberes poderiam dialogar entre si, numa perspectiva de profundo respeito aos sujeitos, suas identidades e culturas. O legado deixado por Freire a partir de "Pedagogia do Oprimido" (FREIRE, 1987), continuou a ser reelaborado pelo próprio autor até a data de seu falecimento, na década de 1990, e por outros intelectuais que se dedicam a aprofundar e agregar novos elementos a esta perspectiva dialógica em função dos desafios históricos que emergem da sociedade nos mais distintos contextos.

Tal movimento pode ser visualizado na citação a seguir, retirada de estudo recentemente concluído por Costa (2018, p. 35):

Podemos relacionar os constructos teóricos de Freire (1967, 1987, 1983, 1996, 2006) ao pensamento de outros autores que igualmente discutem as relações de poder e opressão às quais homens e mulheres dos mais distintos países do mundo vêm sendo historicamente submetidos, como Quijano (2009) ao abordar a colonialidade do poder, os modos como se institui e suas formas de superação; Santos (2009), ao tratar do pensamento abissal, apresentando a ecologia de saberes e as epistemologias do sul como referências para sua superação; Walsh (2013), ao abordar o pensamento decolonial, visando a construção de sentidos mais amplos para o pensamento e fazer pedagógico, através da inspiração de movimentos de rebeldia e desobediência em defesa da pluralidade; Araya (2017), que propõe um movimento decolonial na Didática e sua ressignificação, tendo como horizonte a construção de uma formação de natureza emancipatória; Gomes (2012), discutindo a relações etnicorraciais na perspectiva da educação e da descolonização dos currículos e Candau (2011), ao problematizar as diferenças culturais no cotidiano escolar e nas práticas pedagógicas. Destacam-se, ainda, na perspectiva emancipadora da formação de professores, autores como Pimenta (2005a, 2006, 2016), Lima (2001, 2012), Franco (2003, 2015), Nóvoa (1992, 1995 e 2017), entre outros que reconhecem esses profissionais como sujeitos historicamente capazes de construir conhecimentos relevantes sobre a docência, a partir da problematização de suas vivências formativas e do exercício da docência.

Como é possível visualizar, temas que se dedicam ao desvelamento das relações assimétricas de poder e o papel exercido pelos processos formativos como estratégias tanto de reprodução, quanto de superação dos mesmos, têm ganhado espaço e traduzido perspectivas emancipatórias do Vir a Ser da Educação. Esta é compreendida pelo conjunto de autores apresentados como prática social situada, mergulhada no universo de tensões e contradições que são próprias de uma sociedade recortada em classes e que atualiza, a partir deste recorte, e de outras referências, como étnico-raciais, religião, gênero e orientação sexual, por exemplo, formas de preconceito, discriminação e desumanização.

Pesquisas desenvolvidas no campo da formação de professores têm anunciado o potencial emancipatório proporcionado por perspectivas formativas críticas e reflexivas, pautadas na dialogicidade, na valorização dos saberes da experiência, da problematização das trajetórias de vida, trabalho e formação dos educadores em que estão situados os desafios 
vividos pelos sujeitos nos processos de construção de si. É através desse movimento que os profissionais se dão conta dos nexos estabelecidos, por exemplo, entre as dimensões individuais e coletivas da existência dos sujeitos, que são afetadas de maneira direta pelas políticas sociais e pelos princípios e valores que as fundamentam.

Franco (2015) fazendo menção às práticas educativas aponta que o nível e profundidade das aprendizagens se processa a partir da densidade com que estas são tecidas no diálogo com o outro, considerado fundamental à compreensão dos modos como cada sujeito se relaciona com o saber. Segundo a autora, é nesse movimento que a Pedagogia se afirma como ciência e colabora para o entendimento dos aspectos teóricos e práticos constituintes da práxis, das contradições neles presentes e, sobretudo, traduzidas nos movimentos de ruptura e conservação que colocam em evidência a visão de mundo e valores dos sujeitos, explicitando a favor de que, a favor de quem e de que projeto de sociedade desenvolvem o seu trabalho. Ao pautar, de forma crítica e refletida, esse diálogo com a realidade, os processos formativos assumem compromisso com a emancipação humana que rompe com a alienação que faz com que os sujeitos sejam incapazes de perceber a si mesmos e a relação de suas ações com a totalidade.

Alarcão (2011), ao apresentar a concepção de escola reflexiva, como lugar de construção coletiva de conhecimentos, nos diz que as marcas dessa sociedade contemporânea em que vivemos, expressas na competitividade e no individualismo, entre outras tantas questões, se aproximou demasiadamente das pessoas, alienando-as do processo de construção de si mesmas. A partir do exposto, aponta para a urgência da afirmação da escola como espaço de construção e vivência da cidadania, que se materializa através da leitura da realidade e da ação concreta pautada no exercício da liberdade e da responsabilidade, na atenção, interesse e respeito pela diversidade presente no outro, iluminando a correta tomada de decisões que envolve o comprometimento com as condições de desenvolvimento humano e de seus contextos de vivência.

Tal exercício, convém ressaltarmos, é uma construção cotidiana que leva tempo para se consolidar como práxis, tendo em vista a pressão exercida pelo contexto que busca, através de estratégias diversas, silenciar a voz dos educadores, negar a dimensão política e de sua formação e de seu exercício profissional, por vezes, criminalizando o exercício do diálogo e da leitura crítica da realidade que são necessários às superações das condições de opressão alimentadas em nosso país desde os tempos de colônia.

Nos interessa problematizar, por ocasião da formação de professores, os reflexos que as experiências formativas, desenvolvidas nos contextos formais e informais, deixam na construção da identidade dos docentes. Ao permitir a expressão das angústias e incertezas, medos e ousadias, derrotas e conquistas, por parte dos professores em processos de formação, vamos construindo espaços não só de aprendizagem da escuta e da convivência, mas espaços de solidariedade, de aceitação do outro, da escuta e olhar sensível, de mobilização e luta por espaços dignos de trabalho comprometidos com o respeito à diversidade e busca permanente de humanização.

No movimento de apropriação das próprias trajetórias de vida, trabalho e formação, os professores vão se tornando autores das suas histórias e da sua profissão, ressignificando 
coletivamente teoria e prática, a partir das reflexões que tecem sobre os horizontes formativos propostos pelas políticas educacionais e seus impactos na construção da sociedade.

\section{Desafios da aprendizagem do diálogo: com a palavra, os professores da educação básica}

O movimento investigativo-formativo que possibilitou a construção dos dados que seguirão apresentados nessa seção, buscou, além de promover a construção de conhecimentos acerca do diálogo, criar condições para que os sujeitos que dela participaram compreendessem melhor a si mesmos, os sentidos e significados de suas ações, numa perspectiva de autoconhecimento e transformação da realidade.

Participaram da pesquisa treze professores que atuam em uma Escola Pública Municipal, sendo onze do sexo feminino e dois do sexo masculino, com formações em áreas distintas, atuação nos anos finais do Ensino Fundamental, acumulando em média 11 anos de profissão. A produção de dados foi realizada a partir do desenvolvimento de "Círculos Reflexivos Dialógicos". Esta estratégia investigativa e formativa "[...] toma como ponto de partida o professor como pessoa e segue em um movimento espiral da ampliação das experiências para o campo intersubjetivo no qual o sujeito se reconhece como parte de um grupo, que o afeta e é por ele afetado" (COSTA, 2018, p. 50). Os achados são apresentados a seguir.

Para dar início às discussões sobre Dialogicidade, tomamos como ponto de partida a existência dos próprios professores participantes, suas trajetórias e as aprendizagens construídas ao longo das mesmas que permitiram os movimentos de aproximação e distanciamento com a prática do diálogo. Nas reflexões trazidas pelos professores identificados com o nome de cidades da região do Maciço de Baturité/Ceará em que está situado o seu contexto de trabalho - percebemos a predominância da compreensão do diálogo como movimento que se dá na relação eu-tu, presente na fala de sete sujeitos, que destacam como elementos necessários à dialogicidade atributos vinculados aos indivíduos, como abertura ao outro e ao exercício da escuta:

Dialogar é conversar, analisar e refletir com o outro. Estar aberta às decisões, opiniões alheias. Saber ouvir e entender o porquê de certas atitudes e buscar compreender as dimensões da fala (ACARAPE).

Considero que dialogar é o exercício de ouvir o outro, não só de escutar, mas estar aberto ao que o outro pode lhe mostrar como caminho diferente. É, ao mesmo tempo, proporcionar ao outro a oportunidade de lhe conhecer (ARATUBA).

A partir de Freire (1987) compreendemos que a humildade e a amorosidade permitem aos sujeitos a vivência do diálogo autêntico, que supera as relações de poder pautadas no autoritarismo que marcou historicamente a sociedade brasileira. $\mathrm{O}$ exercício de dizer a palavra precisa ser direito de todos e respeitar o lugar da fala do outro e acolhê-lo como sujeito que constrói seu modo de ser e de estar no mundo, a partir de um conjunto de experiências que acumula ao longo de sua existência. Desse modo, as reflexões de Ribeiro 
(2017), dialogam com o pensamento de Freire (1987), quando a autora aponta que "pensar em lugar de fala seria romper com o silêncio instituído para quem foi subalternizado, um movimento no sentido de romper com a hierarquia" (RIBEIRO, 2017, p. 90).

Diante do exposto, é necessário ressaltar que, apesar de a relação eu-tu ser fundamental ao exercício do diálogo, a mesma não é suficiente para a compreensão e transformação da realidade. É necessário considerar a existência dos sujeitos no mundo, na teia de relações que nele se estabelecem. Uma visão mais alargada de diálogo foi apresentada por seis professores, a exemplo de Baturité, quando afirma "A forma com que me vejo e me relaciono com o mundo, as pessoas e tudo o que nos cerca é um diálogo. A relação do que eu penso, falo e faço também é diálogo. Como vejo o outro, a avaliação que faço do mundo, o meu papel como pessoa e profissional, também é diálogo".

O mundo e os determinantes nele presentes afetam o modo como nos relacionamos com nós mesmos, com o outro e com nossos contextos de existência. Sem considerar estes aspectos não é possível construir diálogos autênticos que colaborem com o desvelamento das Situações Limites que nos impedem de Ser Mais. Sem a problematização da realidade as palavras não se transformam em ações, portanto não permitem a emancipação.

O exercício de presença no mundo anunciado por Freire é um desafio permanente posto a todos nós, tendo em vista as experiências formativas que se fizeram presentes ao longo da história do Brasil e de outros países, marcadas pela perspectiva eurocêntrica de imposição de padrões de poder, entendidos como naturais e, portanto, não passíveis de qualquer tipo de questionamento (QUIJANO, 2009). A perspectiva eurocêntrica imprimiu às instituições responsáveis, de forma mais direta pela educação dos sujeitos, como a família e a escola, as marcas do autoritarismo que excluem dos processos formativos a leitura crítica da realidade, reduzindo-os a estratégias de reprodução das relações de poder hegemonicamente estabelecidas na sociedade. Com esta compreensão, seguimos indagando aos professores participantes quais as experiências de diálogos vividas por eles ao longo de suas existências e como estas vêm se dando.

Os professores apresentaram os desafios presentes no exercício de diálogo, colocando em evidência que seus limites e as possibilidades se articulam às relações de poder estabelecidas entre os interlocutores: quanto mais hierárquicas as relações, mais desafiadora é a construção. Dentre as falas expressas pelos professores, algumas indicam a sobreposição de uma opinião sobre a outra de modo mais evidente, como aponta Guaramiranga, quando destaca: "[...] a opinião do sujeito com mais poder, chefias ou patriarcas, normalmente, tem mais peso na decisão final, apresentando um fator determinante, a verticalidade”.

A experiência expressa na fala do sujeito nos permite refletir sobre o movimento oposto à dialogicidade, que é a antidialogicidade. Esta se funda na dominação, na opressão, na redução do outro à condição de objeto a ser manipulado. Assim, antidiálogo e opressão se constituem, de acordo com Freire (1987) como elementos de uma mesma ação.

O ciclo que envolve o antidiálogo e opressão é instaurado e se alimenta a partir da desumanização e da negação do outro. Tudo aquilo e todo aquele que se apresenta como diferente acaba, neste contexto, sendo compreendido como ameaça, como um problema a ser 
resolvido e, por isso, silenciado. Diferenças políticas, de etnia, gênero, orientação sexual, religião, geração entre outras, têm historicamente sido silenciadas nos mais diferentes espaços, desafiando os sujeitos a buscarem formas de articulação para superação desse processo através da resistência que emerge do movimento de conscientização acerca dessa condição e da luta pela expressão das vozes e defesa das identidades e dos direitos.

É importante compreender que a interculturalidade que nos fala da possibilidade de compreensão crítica e convivência democrática das diferentes culturas demanda dialeticamente um movimento de fortalecimento intracultural, que se refere ao empoderamento de cada grupo em específico para que não tenha sua identidade diluída nas relações que estabelece com os demais, na perspectiva da colonialidade (CANDAU, 2017). Algumas tentativas desse fortalecimento são vivenciadas, embora intuitivamente, pelos professores, como anuncia Itapiuna: "Meus professores que sempre me deram conselhos durante minha formação, me apoiando sempre. Essa aproximação aluno-professor é muito importante, pois conseguimos ter um diálogo mais aberto, fazendo com que a aprendizagem seja mais interessante para o aluno".

As tentativas de diálogo junto aos pares, pautadas na partilha de vivências, reflexões e estratégias utilizadas para fazer frente aos desafios postos ao feminino, à juventude, aos coletivos de trabalho e às famílias, conforme anunciado pelos professores, são exercícios importantes de construção identitária dos diferentes grupos, de fortalecimento das relações de solidariedade estabelecidas entre os sujeitos e de empoderamento desses grupos. Este termo é amplo e é abordado por Freire e Shor (1986), a partir da perspectiva de colaborar com o reconhecimento pelos próprios sujeitos e coletivos do poder que eles têm, visando seu engajamento em processos sociais.

A problematização do conjunto de experiências apresentadas pelos professores, articulada com as reflexões tecidas coletivamente, constituíram-se como referências importantes para a compreensão dos modos como são vivenciados os diálogos nos espaços de formação e de profissão, reafirmando o seu potencial formativo e transformador.

\section{Considerações finais}

As políticas educacionais vigentes, no Brasil, carregam em si marcas de uma racionalidade técnica pautada em princípios neoliberais traduzidos nas perspectivas de competitividade e performatividade nos processos de formação desenvolvidos nos diferentes níveis de ensino. Seus principais reflexos na formação inicial de professores se encontram na valorização da dimensão técnica da profissionalidade docente em detrimento das dimensões ética, política e estética que conferem à formação dos sujeitos um caráter emancipatório.

O diálogo se apresenta cada vez mais como um imperativo necessário aos indivíduos e à coletividade para a compreensão de si mesmos e do papel que desempenham na manutenção ou superação das situações-limite postas no atual momento histórico. Assim, é fundamental a compreensão da Educação tanto como uma prática social que se materializa em meio a tensões e contradições, quanto como uma forma de intervenção na realidade que 
permite, segundo os compromissos de quem a promove, mascarar ou desvelar as ideologias que sustentam os projetos de sociedade que caminham em permanente disputa.

O diálogo e a reflexão que emergiram no processo investigativo desencadeado pelos "Círculos Reflexivos Dialógicos" colaboraram para o desvelamento de diferentes elementos presentes na realidade, que dizem respeito às relações que se estabelecem entre os sujeitos, aos diferentes determinantes que afetam dialeticamente a existência dos indivíduos e da coletividade, entre outras referências que permitem compreender tanto as situações-limite que impedem os sujeitos de Ser-Mais, quanto pensar em estratégias de construção do inédito viável, presente no horizonte das utopias em que cada homem e cada mulher se reconhece e se reafirma como sujeito de sua própria história.

Diante dos diferentes achados que emergiram da investigação, podemos compreender que o diálogo se configura como busca constante presente no horizonte das utopias, que ao mesmo tempo em que indica a sua necessidade de evolução e incorporação de novos temas, abordagens e sujeitos, nos permite seguir caminhando em direção a uma educação que possibilite a emancipação dos diferentes sujeitos.

\section{Referências}

ALARCÃO, Isabel. Professores reflexivos em uma escola reflexiva. 8 ed. São Paulo: Cortez, 2011.

BRASIL. Constituição (1988). Constituição da República Federativa do Brasil. Brasília, DF: Senado Federal, 1988.

BRASIL. Lei n ${ }^{\circ} 11.494$, de 20 de junho de 2007. Regulamenta o Fundo de Manutenção e Desenvolvimento da Educação Básica e de Valorização dos Profissionais da Educação Fundeb, de que trata o art. 60 do Ato das Disposições Constitucionais Transitórias; altera a Lei n. 10.195, de 14 de fevereiro de 2001; revoga dispositivos das Leis n. 9.424, de 24 de dezembro de 1996, 10.880, de 9 de junho de 2004, e 10.845, de 5 de março de 2004; e dá outras providências. Diário Oficial da União, Brasília, DF, 21 jun. 2007.

BRASIL. Lei n ${ }^{\circ}$ 9.394, de 20 de dezembro de 1996. Estabelece as diretrizes e bases da educação nacional. Diário Oficial da União, Brasília, DF, 23 dez. 1996a.

BRASIL. Lei n ${ }^{\circ}$ 9.424, de 24 de dezembro de 1996. Dispõe sobre o Fundo de Manutenção e Desenvolvimento do Ensino Fundamental e de Valorização do Magistério, na forma prevista no art. $60, \S 7^{\circ}$, do Ato das Disposições Constitucionais Transitórias, e dá outras providências. Diário Oficial da União, Brasília, DF, 26 dez. 1996 b.

CANDAU, Vera Maria Ferrão. Abecedário de Educação e Interculturalidade. Rio de Janeiro: UFRJ; Cinead, 2017.

CHARLOT, Bernard. Da relação com o saber às práticas educativas. São Paulo: Cortez, 2016. 
COSTA, Elisangela André da Silva. Diálogo pedagógico entre escola e universidade a partir da formação inicial de professores: o caminho e o caminhar da Unilab. 2018. $126 \mathrm{f}$. Relatório (Pós-Doutoral) - Faculdade de Educação. Universidade de São Paulo, São Paulo, 2018.

FRANCO, Maria Amélia Santoro. Práticas pedagógicas de ensinar-aprender: por entre resistências e resignações. Educ. Pesqui., São Paulo, v. 41, n. 3, p. 601-614, jul./set. 2015. http://dx.doi.org/10.1590/S1517-9702201507140384.

FREIRE, Paulo. Educação como prática de liberdade. Rio de Janeiro: Paz e Terra, 1967.

FREIRE, Paulo. Pedagogia do Oprimido. Rio de Janeiro: Paz e Terra, 1987.

FREIRE, Paulo; SHOR, Ira. Medo e ousadia: o cotidiano do professor. Tradução de Adriana Lopez. Rio de Janeiro: Paz e Terra, 1986.

KÖNIG, Erika Himmel. A defesa de uma cultura avaliativa. Cadernos Cenpec, São Paulo, v. 2, n. 3, p. 80-89, jan./jun. 2007. http://dx.doi.org/10.18676/cadernoscenpec.v2i3.2

LIBÂNEO, José Carlos. Adeus Professor, Adeus Professora? Novas exigências educacionais e profissão docente. 13 ed. São Paulo: Cortez, 2011.

PIMENTA, Selma Garrido; LIMA, Maria Socorro Lucena. Estágios supervisionados e o Programa Institucional de Bolsa de Iniciação à Docência: duas faces da mesma moeda? Rev. Bras. Educ., Rio de Janeiro, v. 24, e240001, 2019. https://doi.org/10.1590/s141324782019240001

QUIJANO, Anibal. Colonialidade do poder e classificação social. In: SANTOS, Boaventura de Sousa; MENESES, Maria Paula (org.). Epistemologias do Sul. Coimbra: Edições Almedina, 2009. p. 73-118.

RIBEIRO, Djamila. O que é lugar de fala? Belo Horizonte: Letramentos, 2017.

RIOS, Terezinha Azerêdo. Compreender e ensinar: por uma docência da melhor qualidade. São Paulo: Cortez, 2010.

SILVA, Tomaz Tadeu da. A "nova" direita e as transformações na pedagogia da política e na política da pedagogia. In: GENTILI, Pablo; SILVA, Tomaz Tadeu da (org.). Neoliberalismo, qualidade total e educação. Rio de Janeiro: Vozes, 2001. p. 9-30.

ZEICHNER, Kenneth M. Políticas de formação de professores nos Estados Unidos: como e por que elas afetam vários países do mundo. Tradução de Cristina Antunes. Belo Horizonte: Autêntica, 2013.

\begin{tabular}{|c|c|c|c|}
\hline 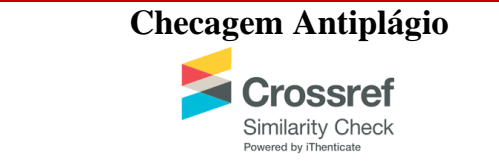 & & Distrib & $\begin{array}{c}\text { ouído sobre } \\
\text { (†) } \\
\end{array}$ \\
\hline Educ. Perspect. | Viçosa, MG & $\mid$ v. $11 \mid$ p. $1-14|\mathrm{e} 020010|$ & 2020 & eISSN 2178-8359 \\
\hline
\end{tabular}

